Original Research Article

\title{
An analysis of adherence to the World Health Organisation guidelines pertaining to drug promotional literature by pharmaceutical firms
}

\author{
Salma Malik, Tejus Anantharamu*, M. Fadil Salmani, Sapna Pradhan, A. G. Mathur
}

Department of Pharmacology, Army College of Medical Sciences, New Delhi, India Province, India

Received: 12 October 2018 Accepted: 01 November 2018

*Correspondence to:

Dr. Tejus Anantharamu, Email: ddmtejus@gmail.com

Copyright: (C) the author(s), publisher and licensee Medip Academy. This is an openaccess article distributed under the terms of the Creative Commons Attribution NonCommercial License, which permits unrestricted noncommercial use, distribution, and reproduction in any medium, provided the original work is properly cited.

\begin{abstract}
Background: Pharmaceutical companies used Drug Promotion Literatures (DPLs) as a major tool to advertise their new products. World Health Organization (WHO) has set some guidelines for promotion of drug literature. Thus, this study aimed to evaluate various DPLs for their accuracy and credibility as per WHO ethical criteria.

Methods: This was an observational and cross-sectional study. Total 100 drugs advertisements published in various medical journals were collected from the library of the college. Advertisements were selected based on inclusion and exclusion criteria. The selected advertisements were evaluated based on the WHO ethical criteria for drug promotion.

Results: From 100 advertisements, 73 were single drug whereas 27 were fixed drug combinations. Antimicrobials (16\%) were the most promoted advertisements. Only $28 \%$ of the advertisements carried references to support their claim. Out of which majority $(91.78 \%)$ were from journal articles. The generic name, brand name, names of active ingredients, manufacturer, distributor and dosage regimen were mentioned in majority of advertisements. Drug interactions $(12 \%)$, contraindications $(22 \%)$, precautions $(24 \%)$ and side effects (22\%) were least mentioned in the advertisements.

Conclusions: It was observed that none of the advertisement followed all the guidelines laid down by WHO. Pharmaceutical companies should follow ethical regulatory measures to promote their product in various journals. The regulatory authority must ensure the pharmaceutical companies to follow ethical guidelines for publishing various drug promotional literatures.
\end{abstract}

Keywords: Drug advertisements, Indian medical journals, WHO criteria of drug promotion literature

\section{INTRODUCTION}

A drug as defined by U.S. Food and Drug Administration (FDA) is "A substance recognized by official Pharmacopoeia or formulary, intended for use in diagnosis, cure, mitigation, treatment or prevention of disease, intended to affect the structure or function of the body and intended for use as a component of a medicine but not a device or a component, part, or accessory of a device". ${ }^{1}$ A large number of drugs enter into the market every year, with the year 2017 recording the highest number of approvals in the last two decades with 46 approvals. $^{2,3}$ The role of FDA is to ensure that safe and effective drugs enter the market which has made the approval process a tedious and costly affair, with an average of 12 years for a new drug approval and cost of development exceeding1 billion dollars. ${ }^{1,4}$

Drug promotion is defined by the WHO as "all informational and persuasive activities by manufacturers and distributors, the effect of which is to influence the prescription, supply, purchase or use of medicinal drugs". ${ }^{4}$ The stated aim of drug promotion is to make healthcare 
professionals aware and update their knowledge about the advances in patient care available in the market. ${ }^{1,4}$ Approximately 1 in every 1000 potential drug molecule reaches clinical trial after preclinical testing and 9 out of every 10 being tested in clinical trials fails to reach market. ${ }^{1}$ This phenomenon is almost universal as per data of regulatory bodies of most countries. This has generated stiff competition amongst pharmaceutical companies to generate profit out of the successfully approved drugs. ${ }^{1,4}$

Drug promotion is being carried out vigorously by the pharmaceutical industry at various levels either directly in the form of medical representatives liaising with prescribers, hosting of continuous medical education programmes, conferences or indirectly through print or electronic media. ${ }^{4,5}$ Promotional activities initially were directed towards clinicians, but of late a major focus is also directed towards 'direct-to-customer' advertisements. ${ }^{4}$ In an effort to regulate the promotional activities many national and international guidelines are being framed from time to time such as the WHO Ethical Guidelines, International Federation of Pharmaceutical Manufacturers and Associations (IFPMA) Code of Pharmaceutical Marketing Practices, Organization of pharmaceutical producers of India (OPPI) and Uniform code of Pharmaceutical marketing practices (UCPMP). 2,4,6

Although many guidelines exist the implementation of the same is the key which is the need of the hour. Hence, this study has been conducted to assess the correctness of drug promotional literature using the WHO criteria.

\section{METHODS}

The current study was undertaken as an observational study conducted by the Department of Pharmacology at a medical college in Delhi. Drug promotional literature like advertisements published in various medical journals were collected from the college library between January to March 2018. A total of 100 advertisements were randomly selected and were included in the study. Drug advertisements related to medical equipments and devices, Ayurvedic medicines, nutritional supplements, two brands of the same medicine and duplicate advertisements were excluded from the study.

All the advertisements included in the study were assessed using the WHO ethical criteria for drug promotion which requires the inclusion of the name of the active ingredients - either their international non-proprietary name or approved generic name, brand name, content of active ingredients per dosage form or regimen, other ingredients known to cause problems, approved therapeutic uses, the dosage form/ regimen, side effects and major adverse drug reactions, precautions, contraindications and warnings, major interactions, name and address of manufacturer/ distributor and references to scientific literature. ${ }^{6}$

The references will be further assessed based on their source as from a journal article (randomized controlled trials, observational studies, guidelines, research articles or review articles) or from a book and whether they are retrievable or not. Descriptive statistics were utilized to analyze the data and the results were expressed as percentages.

\section{RESULTS}

Out of 100 drug advertisements included in this study, 73 advertisements promoted single drug formulation and the rest 27 were for fixed dose combinations. The system/ drug group wise distribution of products being promoted were as follows: Antimicrobials (16\%), vitamins and minerals (13\%), drugs affecting gastrointestinal system (13\%), central nervous system (12\%), respiratory system $(10 \%)$, vaccines $(8 \%)$, autacoids and related drugs $(7 \%)$, drugs affecting autonomic nervous system $(6 \%)$, cardiovascular system $(5 \%)$ and miscellaneous (10\%) (Table 1).

\section{Table 1: System/ drug wise distribution of advertisements.}

\begin{tabular}{|ll|}
\hline Drug Groups & $\begin{array}{l}\text { Percentage } \\
(\%)\end{array}$ \\
\hline $\begin{array}{l}\text { Drugs acting on autonomic nervous } \\
\text { system }\end{array}$ & 6 \\
\hline Autacoids and related drugs & 7 \\
\hline Drugs acting on Respiratory system & 10 \\
\hline Drugs affecting central nervous system & 12 \\
\hline Drugs acting on cardiovascular system & 5 \\
\hline Drugs acting on gastrointestinal tract & 13 \\
\hline Antimicrobials & 16 \\
\hline Vitamins and minerals & 13 \\
\hline Vaccines & 8 \\
\hline Miscellaneous & 10 \\
\hline
\end{tabular}

The assessment of advertisements using WHO criteria is as mentioned in Table 2. All the selected advertisements mentioned brand names with most of them publishing the generic names as well (97\%). $96 \%$ of the advertisements mentioned dosage forms whereas only $31 \%$ have brought out the regimen for administering the dose. Majority of advertisements (96\%) have clearly brought out the therapeutic uses.

A higher percentage (92\%) of the advertisements mentioned the name(s) of the active ingredient(s) whereas only $2 \%$ mentioned the other ingredients known to cause problems. The advertisements were poorly compliant in bringing out the precautions needed to be taken by the consumers with only $24 \%$ bringing out the precautions. The predictors of adverse drug reactions like side effects are brought out by only $22 \%$ of advertisements and contraindications by $22 \%$. The other WHO to which advertisements were poorly compliant was warnings $(19 \%)$ and major interactions (12\%).

Out of 100 advertisements only $28 \%$ carried references to scientific literature. In these advertisements, a total of 73 
references were quoted, amongst which $91.78 \%$ were from journal articles and $4.11 \%$ were from websites and books respectively (Figure 1). Out of these references 4 were non-retrievable: 3 from journal articles and 1 from a textbook. Furthermore, references from journal articles were classified as per study design such as randomized controlled trials $(37.31 \%)$, observational studies $(16.41 \%)$, guidelines $(4.48 \%)$, research articles $(4.48 \%)$ and review articles $(32.83 \%)$. (Figure 2).

Table 2: Analysis of drug advertisements using WHO criteria.

\begin{tabular}{|ll|}
\hline WHO criteria & $\begin{array}{l}\text { Percentage of } \\
\text { advertisements } \\
\text { complying (\%) }\end{array}$ \\
\hline Brand name & 100 \\
\hline Generic name & 97 \\
\hline Content of active ingredients & 92 \\
\hline $\begin{array}{l}\text { Other ingredient known to cause } \\
\text { problems }\end{array}$ & 02 \\
\hline Dosage forms & 96 \\
\hline Dosage regimen & 31 \\
\hline Therapeutic uses & 96 \\
\hline Side effects & 22 \\
\hline Precautions & 24 \\
\hline Contraindications & 22 \\
\hline Warnings & 19 \\
\hline Major interactions & 12 \\
\hline Reference to scientific literature & 28 \\
\hline $\begin{array}{l}\text { Name of manufacturer and } \\
\text { distributor }\end{array}$ & 96 \\
\hline $\begin{array}{l}\text { Address of manufacturer and } \\
\text { distributor }\end{array}$ & 70 \\
\hline
\end{tabular}

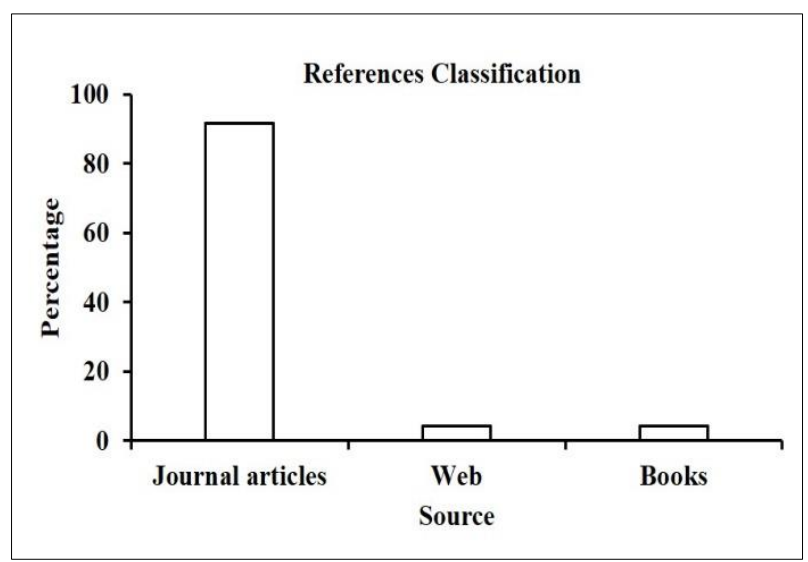

Figure 1: Classification of references to scientific literature in advertisements.

\section{DISCUSSION}

The pharmaceutical advertisements in various medical journals are used as a method to disseminate information on various new drug arrivals to the prescribing physicians. ${ }^{7-9}$ As these advertisements can potentially influence the prescribing nature of physicians it is necessary that the information carried by them must be valid and the claims made by them must be supported by suitable scientific literature. ${ }^{7,8}$ Many critics have raised concerns regarding rationality of the information presented in these advertisements and poor referencing. ${ }^{8}$

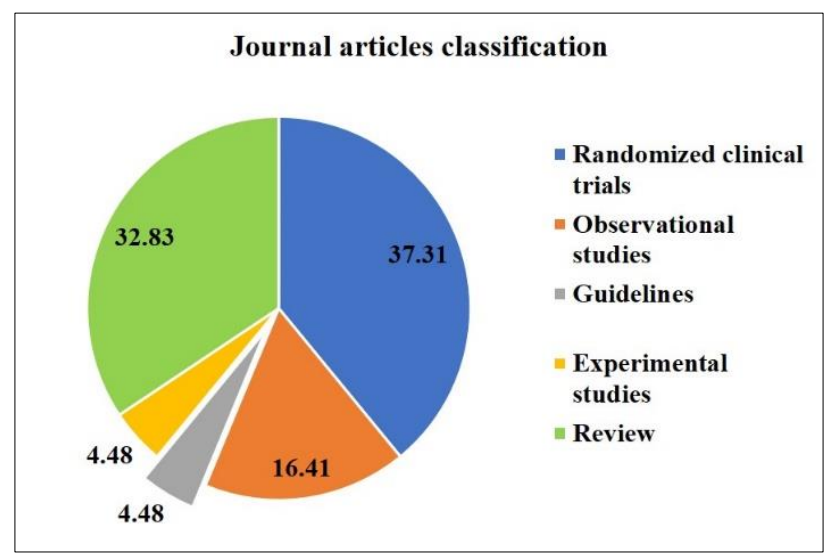

Organization of pharmaceutical Producers of India (OPPI) and Uniform Code of Pharmaceutical Marketing Practices (UCPMP)

\section{Figure 2: Classification of journal references to scientific literature as per study design.}

Unethical drug advertisements have been noticed in the medical journals of various countries. ${ }^{7}$ Hence our study was an effort to evaluate the advertisements published in various journals read by the faculty in a medical college with respect to their compliance with WHO ethical guidelines for drug advertisements. In this study it was observed that $73 \%$ of the advertisements promoted single drug formulation. Charan $\mathbf{J}$ et al, in their study of drug advertisements obtained similar results wherein $72.3 \%$ of the evaluated advertisements were of single drug. Antimicrobials topped the list of most advertised drug groups in concurrence with other studies. ${ }^{2,7}$

In this study it was noticed that none of the advertisements fully satisfied the WHO criteria except for the brand name. The generic names, content of the active ingredients and dosage forms were published in most advertisements. In concurrence with our results Nath $\mathrm{S}$ et al, demonstrated that majority of drug advertisements carried brand names $(100 \%)$, contents of active ingredients $(95.17 \%)$, dosage forms $(81.37 \%) .{ }^{10,11}$ Furthermore, it is seen that there appears to be greater adherence to the guidelines by the advertisements in this study as compared to Nath $\mathrm{S}$ et al, in regard to therapeutic uses (95\% vs. $61.37 \%)$, side effects (22\% Vs $1.37 \%)$, contraindications (22\% Vs $1.37 \%)$ and major interactions $(12 \% \mathrm{Vs} 0 \%) .{ }^{10}$ This gives a positive outlook as there appears to be a greater adherence to ethical guidelines.

It was observed that only $28 \%$ advertisements have given references to show authenticity of their data in concurrence with Naikwadi SA et al. ${ }^{7,12}$ In a similar pattern maximum references were from review articles. ${ }^{12}$ The study has some 
limitations, as we have collected data only from 100 advertisements. The study however does serve to underscore the fact that physicians should encourage the pattern of ethical promotion of literature and any unethical advertisement should be reported to one of the regional ethics committees located at Mumbai, Chennai, New Delhi and Chandigarh so that they can take legal steps against guilty companies.

\section{CONCLUSION}

Pharmaceutical advertisements are used as a medium for dissemination of drug information. The study tried to analyse their compliance to WHO criteria. The pattern of following ethical guidelines while publishing drug advertisements although followed but not in its totality. Hence it is the task of regulatory agencies not only to define guidelines for publishing drug advertisements but also to ensure its complete implementation.

Funding: No funding sources

Conflict of interest: None declared

Ethical approval: Not required

\section{REFERENCES}

1. Van Norman GA. Drugs, devices, and the FDA: Part 1: an overview of approval processes for drugs. JACC: Basic Transl Sci. 2016 Apr 25;1(3):170-9.

2. Ganashree P, Bhuvana K, Sarala N. Critical review of drug promotional literature using the World Health Organization guidelines. J Res Pharm Pract. 2016;5(3):162-5.

3. Mullard A. 2017 FDA drug approvals. Nat Rev Drug Discov. 2018;17(2):81-5.

4. Jacob NT. Drug promotion practices: A review. Br J Clin Pharmacol. 2018;84(8):1659-67.

5. Pascal Iloh GU, Chukwuonye ME. Drug promotion in a resource-constrained Nigerian environment: A cross-sectional study of the influence of pharmaceutical sales representatives on the prescribing behaviors of medical practitioners in Abia State. Arch Med Health Sci. 2017;5(2):215-22.

6. Ethical criteria for medicinal drug promotion. World Health Organ (online). 1988;13:1-22. Available at: http://www.who.int/medicinedocs/collect/edmweb/pd f/whozip08e

7. Charan J, Yadav P, Saxena D, Kantharia ND. Drug advertisements published in Indian Medical Journals: Are they ethical? J Pharm Bioallied Sci. 2011;3(3):403-6.

8. Korenstein D, Keyhani S, Mendelson A, Ross JS. Adherence of Pharmaceutical Advertisements in Medical Journals to FDA Guidelines and Content for Safe Prescribing. PloS One. 2011;6(8):233-36.

9. Jaykaran, Saxena D, Yadav P, Kantharia ND. Drug promotional literature distributed by pharmaceutical companies: Do they provide enough. J Pharmacol Pharmacother. 2011;2(3):193-4.

10. Nath S, Bhowmick S, Dutta T, Chowrasia VR, Bhattacharya S, Chatterjee RN, et al. A study of promotional advertisements of drugs in a medical journal: an ethics perspective. Ind J Med Ethic. 2014 Oct;11(4).

11. Mali SN, Dudhgaonkar S, Bachewar NP. Evaluation of rationality of promotional drug literature using World Health Organization guidelines. Indian J Pharmacol. 2010;42(5):267-72.

12. Naikwadi SA, Jadhav RB, Patil AP. Critical analysis of Indian drug promotional literature (DPL) using World Health Organization criteria for ethical medicinal drug promotion. ISOR-JDMS. 2017;16(9):49-54.

Cite this article as: Malik S, Anantharamu T, Salmani MF, Pradhan S, Mathur AG. An analysis of adherence to the World Health Organisation guidelines pertaining to drug promotional literature by pharmaceutical firms. Int J Basic Clin Pharmacol 2018;7:2429-32. 